\title{
Modelo de negócios em plataforma digital para comercialização de flores no Brasil
}

\section{Digital platform business model for flower marketing in Brazil}

\author{
Milton Hummel Mestre em Administração do Desenvolvimento de Negócios. Universidade Presbiteriana \\ Mackenzie (UPM) - Brasil. hummel.milton@gmail.com \\ Adilson Aderito da Silva Doutor em Administração de Empresas. Universidade Presbiteriana Mackenzie (UPM). Brasil. \\ adilson.asilva@mackenzie.br
}

\section{RESUMO}

O conceito de plataforma digital desponta como um dos grandes eixos de inovação nos últimos anos e tem sido desenvolvido e implantado em diversos segmentos da economia, tanto por startups quanto por grandes empresas. Neste trabalho apresenta-se um relato sobre a criação e a implantação de uma plataforma digital em uma Cooperativa do Brasil destinada à comercialização de flores e plantas ornamentais no segmento B2B. O relato está embasado na metodologia Business Problem Solving que engloba o entendimento do problema/oportunidade, o diagnóstico, a proposta de solução, o plano de ações e a intervenção sobre a realidade investigada. Com o diagnóstico desse segmento foi possível reconhecer os potenciais ganhos com o novo modelo de negócios, com destaque para as transações com contrato de mercado futuro, transações presentes com menores níveis de perdas, menores custos de transação aos cooperados e maior comodidade aos compradores. Por seu ineditismo, a implantação da plataforma é uma inovação no setor e tem criado um efeito de rede positivo e crescente, elevado o faturamento, a rentabilidade e gerado diferenciais competitivos para todos os participantes. O estudo aponta ainda oportunidades para estender e aplicar o novo modelo em outros segmentos de produtos perecíveis do mercado agrícola de médio porte, como é o caso da Cooperativa Estudada.

Palavras-chave: Plataforma Digital. Inovação. Mercado B2B. Plantas Ornamentais. Cooperativismo.

\begin{abstract}
The concept of the digital platform has emerged as one of the great axes of innovation in recent years. It has been developed and implemented in various segments of the economy, both by startups and large companies. This paper presents an account about the creation and implementation of a digital platform in a cooperative in Brazil dealing with the commercialization of flowers and ornamental plants in B2B Market. This paper is based on the Business Problem Solving methodology that encompasses the understanding of the problem/opportunity, diagnosis, solution proposal, action plan and intervention on the reality investigated. From the diagnosis of this market, it was possible to recognize the potential gains with the new business model, especially transactions with futures market contracts, transactions with lower levels of losses and transaction costs to the cooperative members, and greater convenience to buyers. The implementation of the digital platform is an unprecedented innovation in the sector and has created a growing network effect by increasing revenue, profitability, and competitive differentials generated for all participants. The study also points out opportunities to extend and apply the new model in other segments of perishable products in the medium-sized agricultural market, such as the cooperative studied.
\end{abstract}

Keywords: Digital platform. Innovation. B2B Market. Ornamental plants. Cooperativism. 


\section{INTRODUÇÃO}

A comercialização de plantas ornamentais é muito diversa e ampla, envolve flores de corte, folhagens, bulbos, vasos de flores, vasos de plantas verdes, forrações e plantas para paisagismo, representando um mercado mundial que movimenta cerca de US\$ 90 bilhões/ano (VAN RIJSWICK, 2016).

A maioria das flores de corte, folhagens e bulbos de flores, segundo a pesquisa da World Floriculture Map, de 2016, conduzida por Van Rijswick (2016), é produzida no hemisfério sul onde se destacam como principais produtores a Colômbia e o Equador, países esses que mais se diversificaram na produção de rosas de corte, crisântemos e cravos exportados para os mercados do hemisfério norte.

No Brasil, a produção e a comercialização de flores e plantas intensificaram-se por volta de $1940 \mathrm{com}$ a chegada dos imigrantes europeus, de origem portuguesa e italiana, que destinavam suas produções aos eventos comemorativos e decorações das festas de luxo demandadas pela alta sociedade paulistana (TSUBOI; TSURUSHIMA, 2009). Com a chegada dos alemães e poloneses, na região Sul do país, dos holandeses, na região de Holambra, e dos japoneses, na região de Atibaia, deu-se origem a três polos produtivos, que ainda permanecem, e, cuja maioria, está localizada no Estado de São Paulo destacando-o como maior estado produtor brasileiro.

O segmento de flores e plantas ornamentais, por sua origem, tem o modelo de cooperativismo como predominante e duas das maiores e mais modernas cooperativas de produtores brasileiras se localizam no Estado de São Paulo. Conforme Neves et al. (2015), essas duas cooperativas se servem de bases sólidas para comercialização estruturada de aproximadamente $90 \%$ da produção de flores e plantas ornamentais no Brasil. Diante da intensa concorrência e da elevada demanda neste segmento a busca por oportunidades de mercado e maior diferenciação da oferta de produtos aos clientes são constantes. Dessa forma, a inovação tem sido um dos eixos estratégicos para criar condições adequadas de vendas para todos os produtores, desde os menores até os mais estruturados.

A inovação neste segmento se caracteriza tanto pela produção de novas variedades, que se apresentam com maior nível de produtividade, maior durabilidade no pós-colheita e com cores e formatos distintos para uma melhor rentabilidade para os produtores, como pela diversificação das formas de comercialização mais ágeis e eficientes para se evitar perdas decorrentes do elevado grau de perecibilidade dos produtos e da alternância da demanda ao longo do ano, fatores esses que elevam a complexidade da gestão comercial dos produtos.

Considerando a elevada perecibilidade dos produtos e o desafio da comercialização pelo melhor preço com o menor nível de perda de produtos, ao longo dos anos as Cooperativas adotaram, basicamente, três modelos de comercialização: a) o leilão reverso Klok originário das cooperativas holandesas que, além de acelerar a comercialização, funciona como um regulador do mercado, b) a intermediação das vendas, e c) vendas on-line.

Não obstante à eficácia do modelo de leilão Klok para regular os preços no mercado, este tem sido questionado mundialmente. Nesse tipo de comercialização, quando o produto não atinge o preço mínimo estabelecido, este deve ser descartado, acarretando perdas aos produtores. Por outro lado, o modelo atual de negociação com os atacadistas de flores, varejistas alimentares e não alimentares, realizado com o suporte de sistema de gestão de vendas, não tem fomentado a competição entre os produtores cooperados, inibindo com isso que estes sejam mais criativos e ousados em suas produções.

A partir do exame dos dados provenientes dos polos produtivos e dos centros de comercialização, foco deste estudo, identificou-se os principais fatores de influência e de restrições ao crescimento e à criação de valor aos negócios desse segmento, e com isso desvelou-se a oportunidade para desenvolver um novo modelo de comercialização de flores, com abrangência nacional, de forma coordenada e cooperativista, baseado no conceito de plataforma digital.

O modelo de negócios em plataforma digital é recente e não há experiências similares quanto a sua implantação no segmento de flores e produtos ornamentais. Assim, o desenvolvimento deste estudo além de reunir maior conhecimento sobre esse modelo de negócios, traz novos aprendizados, novos horizontes, maiores expectativas de ganhos e agregação de valor aos cooperados tanto na oferta quanto na 
comercialização de produtos, a médio e a longo prazo. Neste estudo apresenta-se um relato de como se deu o desenvolvimento e a implantação de um novo modelo de negócios em plataforma digital para comercialização de flores e plantas ornamentais, capaz de realizar vendas diretas com alcance rápido de potenciais consumidores e novos cooperados em diversas regiões do país.

O desenvolvimento deste trabalho está embasado na metodologia Business Solving Problem utilizada por Aken, Berends e Bij (2012) e Vandenbosch (2003). Esta metodologia, que tem sido utilizada como parâmetro para a elaboração e planejamento de soluções organizacionais e trabalhos aplicados de conclusão em cursos de Mestrados Profissionais e de Pós-graduação em Administração no Brasil, envolve as etapas de entendimento de um problema ou de uma oportunidade, o diagnóstico da situação enfrentada, a elaboração de medidas alternativas, o plano de ação da mudança, e a intervenção na realidade investigada sem, contudo, dispensar a fundamentação teórica na proposição de soluções e identificação das oportunidades. (RODRIGUES; CALDEIRA, 2019; MARCONDES et al., 2017)

Nesse sentido, o artigo se resume a um recorte temporal que se estende desde os primeiros direcionamentos a partir da identificação da oportunidade até o início da implantação da plataforma digital e seus primeiros resultados. Além desta introdução, são apresentados os cenários da comercialização de flores ornamentais, abordando-se o mercado mundial e o mercado de flores e plantas brasileiro. A seguir, apresentase o ambiente de atuação das Cooperativas, a identificação dos fatores que exercem pressão e impõem restrições ao crescimento do setor. Na quarta seção, apresenta-se a fundamentação teórica que embasa a implantação do modelo de negócios em plataforma, suas estruturas de base, o efeito da externalidade de rede, as formas de monetização, modelos de governança e os fatores críticos de sucesso (FCSs).

\section{CONTEXTO E REALIDADE INVESTIGADA}

Neste tópico apresentam-se os cenários da comercialização de flores ornamentais, partindo do mercado mundial até o mercado de flores e plantas brasileiro. Busca-se reunir maior entendimento sobre a produção brasileira deste segmento a partir do histórico de comercialização com vistas a explorar as potencialidades da plataforma em alcançar mercados para os produtos.

\subsection{0 mercado de flores no mundo}

O setor de plantas ornamentais mundial é muito diverso e amplo, incluindo a produção de flores de corte, folhagens, bulbos, vasos de flores, vasos de plantas verdes, forrações e plantas para paisagismo, sendo a estimativa do mercado total de US\$ 90 bilhões (VAN RIJSWICK, 2016). O ponto interessante do mercado mundial é que somente as flores de corte, as folhagens e os bulbos de flores possuem um mercado globalizado, sendo a maioria delas produzidas no hemisfério sul e exportadas para o hemisfério norte, enquanto os outros produtos são consumidos mais próximos de suas regiões produtoras.

A principal razão para que isso ocorra é fitossanitária, pois os substratos dos vasos possuem restrições de transportes internacionais, visando a prevenção da propagação de doenças entre os diferentes países. No estudo World Floriculture Map conduzido por Van Rijswick (2016), observa-se uma importante participação de quatro países do hemisfério sul: Colômbia, Quênia, Equador e Etiópia (figura 1). 
Figura 1 - Fluxo de negócios de flores de corte, folhagens, bulbos de flores em 2015

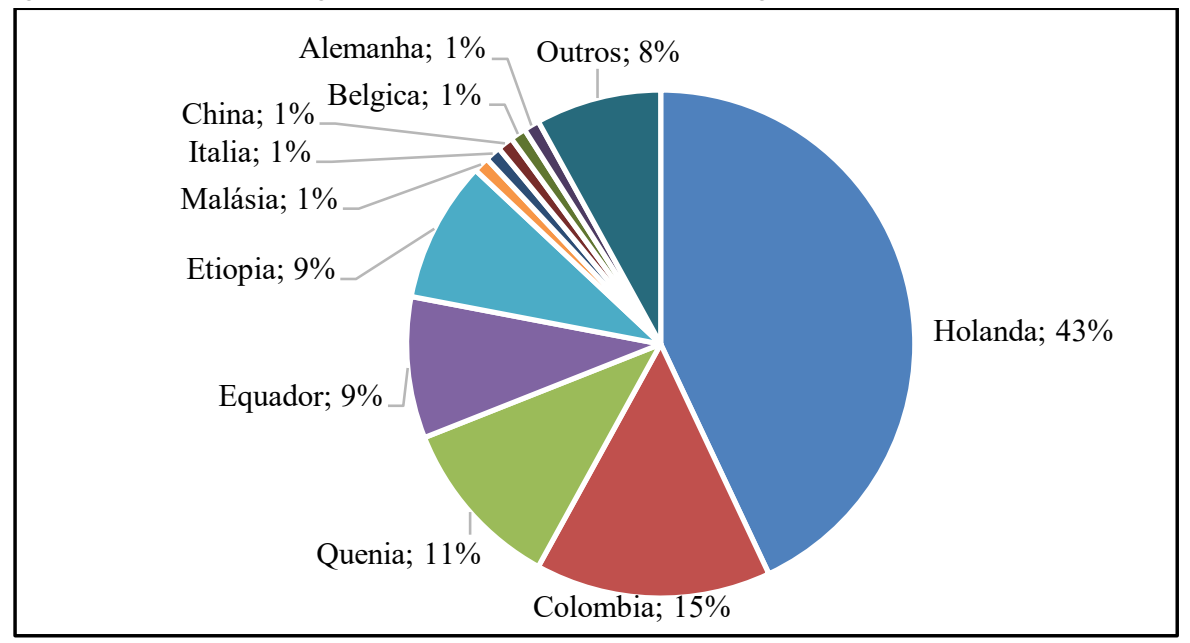

Fonte: Van Rijswick (2016)

Esses polos produtivos são recentes e representavam $44 \%$ do fluxo mundial, uma representação expressiva comparada àquela registrada dez anos antes no patamar de $25 \%$. Ao longo desse período a Colômbia foi o país que mais se diversificou, com crisântemos e cravos de corte. Os outros três países possuem forte concentração em rosas de corte. Entretanto, para os quatro países há vantagens produtivas, como o clima adequado, mão de obra barata e grandes áreas produtivas. Por outro lado, observam-se algumas desvantagens, tais como: fluxo aéreo logístico, baixo consumo interno, riscos políticos e taxas cambiais inconstantes.

De acordo com a pesquisa do Retail Feedback Group, realizada em 2015, mais de 40\% dos consumidores mundiais, entre todas as gerações e idades, consomem flores de 3-4 vezes por ano. Essa pesquisa também mostrou que os consumidores buscam, em escala de prioridade, a qualidade, o frescor, o preço e a variedade dos produtos ofertados.

\subsection{A produção de flores no Brasil}

A produção de flores e plantas no Brasil até 1940 era conduzida pelos imigrantes europeus de origem portuguesa e italiana e estava destinada ao consumo nos momentos de visitas a cemitérios, decorações das casas da alta sociedade paulista e ao atendimento das demandas de luxo para festas. Naquela época predominava a produção amadora, precária em condições de produção, e em capacidade para suprir a demanda potencial do país (TSUBOI; TSURUSHIMA, 2009).

Durante o processo evolutivo da produção de flores foram criados três eixos produtivos: 1) desenvolvido pelos holandeses na região hoje pertencente ao município de Holambra; 2) pelos japoneses em Atibaia e Arujá, e 3) pelos alemães e poloneses nos Estados de Santa Catarina e Rio Grande do Sul.

Cabe ressaltar que a produção brasileira de flores ainda está direcionada para o mercado interno, sendo a exportação um mercado secundário que está concentrado nos segmentos de bulbos, rizomas e tubérculos, assim como em mudas de plantas ornamentais (NEVES et al., 2015). Contudo, no passado recente as exportações foram mais expressivas até a crise mundial de 2008, a partir da qual houve um movimento de redução que continuou até o ano de 2014.

Nos últimos 10 anos, apesar de oscilarem, as exportações diminuíram 6,1\% em relação ao ano de 2008 e alcançaram o valor de US\$23,8 milhões no ano de 2014. O estudo apresentado por Neves et al. (2015) também revelou que o Produto Interno Bruto (PIB) da cadeia produtiva de Flores e Plantas Ornamentais do Brasil, em 2014, foi de $\mathrm{R} \$ 4,51$ bilhões (tabela 1). 
Tabela 1 - Estimativa do Produto Interno Bruto da Cadeia Produtiva de Flores e Plantas Ornamentais em 2014

\section{Produto}

Floricultura

Decoração

Paisagismo

Autosserviço

Atacados consumidor final

Produtores consumidor final

Exportação

Importação

Total

4.540.582.813

649.395 .492
Mercado Externo (R\$)

984.330 .709

2.340.728.679

385.161 .923

120.700 .722

60.265 .288
Total E) (R\$)

984.330 .709

2.340.728.679

649.395 .492

385.161 .923

120.700 .722

60.265 .288

55.958 .381

$-83.004 .272$

Fonte: Neves et al. (2015)

A distribuição regional da produção corrobora a importância dos polos localizados no Estado de São Paulo com a larga vantagem produtiva da Região Sudeste, com mais de $80 \%$ da produção nacional em flores e folhagens de corte e nas flores e plantas envasadas.

Tabela 2 - Participação percentual relativa das macrorregiões geográficas no Mercado dos diferentes segmentos do mercado de flores e plantas ornamentais, em 2013

\begin{tabular}{cccc}
\hline & \multicolumn{3}{c}{ Setores (\%) } \\
\cline { 2 - 4 } Regiões & $\begin{array}{c}\text { Flores e folhagens de } \\
\text { corte }\end{array}$ & $\begin{array}{c}\text { Flores e plantas } \\
\text { envasadas }\end{array}$ & $\begin{array}{c}\text { Plantas para paisagismo e } \\
\text { jardinagem }\end{array}$ \\
Sudeste & 83,02 & 83,48 & 60,41 \\
Sul & 2,9 & 8,12 & 16,57 \\
Centro-Oeste & 1,54 & 1,14 & 9,95 \\
Nordeste & 9,92 & 6,87 & 9,51 \\
Nordeste & 9,92 & 6,87 & 9,51 \\
Norte & 2,62 & 0,39 & 3,56 \\
Total & 100 & 100 & 100 \\
\hline
\end{tabular}

Fonte: Sebrae (2015).

Na divisão por estados, em estudo apresentado pelo Instituto Brasileiro de Floricultura, IBRAFLOR (2015), a área plantada de flores e plantas ornamentais era aproximadamente 15.000 hectares, com 8.248 produtores dedicando-se a esta atividade. A referência produtiva de flores no Brasil é o Estado de São Paulo onde se destacam as regiões produtoras de Holambra, Atibaia, Ibiúna e Mogi das Cruzes, regiões essas onde estão as maiores e mais modernas cooperativas de produtores de flores e que geram bases sólidas de comercialização estruturada de flores e plantas ornamentais no Brasil (NEVES et al., 2015).

A concentração alimentada pelas estruturas cooperativistas de comercialização localizadas no Estado de São Paulo atinge cerca de 37\% do total nacional. Além das cooperativas localizadas na Região de Holambra, destacam-se a Companhia de Entrepostos e Armazéns Gerais de São Paulo (Ceagesp de São Paulo), o Mercado Permanente de Flores e Plantas Ornamentais da Ceasa Campinas, pequenas Ceasas locais como o de Ribeirão Preto, Sorocaba e Santo André e a Cooperativa SP Flores de Mogi das Cruzes. No restante do Brasil há outros 
15 centros representativos de distribuição atacadista de flores e plantas ornamentais instalados principalmente em unidades de Ceasa (NEVES et al, 2015).

Figura 2 - Faturamento brasileiro de flores e plantas ornamentais por estado em 2014

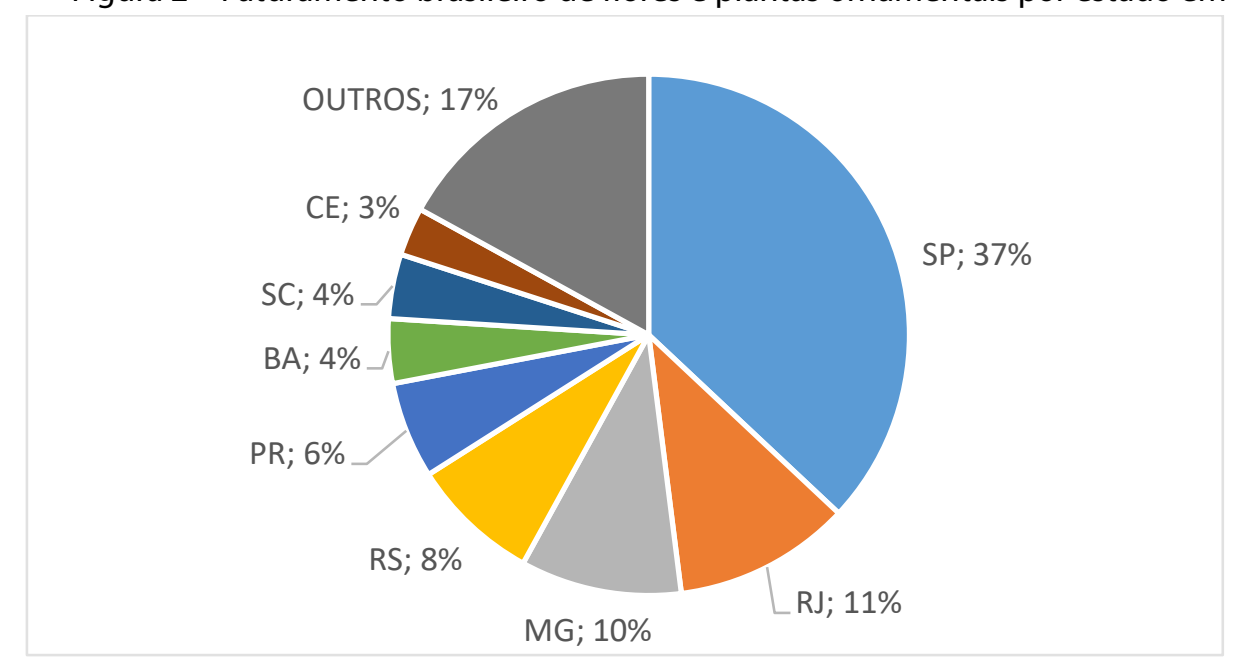

Fonte: Ibraflor (2015)

O segundo Estado produtor, o Rio de Janeiro, possui polos de produção de flores e plantas ornamentais em: Região Metropolitana, Noroeste, Serrana, Centro-Sul, Sul, Norte e Litorânea do Estado. Já em Minas Gerais destacam-se as regiões de Andradas, Munhoz e Barbacena, sendo as duas primeiras fortemente conectadas com as Cooperativas da Região de Holambra. Por último, destacam-se as regiões produtoras do Estado do Rio Grande do Sul, que possuem onze polos de produção: Região do Litoral Norte, São Sebastião do Caí, Planalto, Santa Maria, grande Porto Alegre (Metropolitana), Serra Gaúcha, Santa Cruz do Sul, Noroeste, Lajeado, Sul e das Hortênsias (NEVES et al., 2015).

O perfil predominante para a produção de flores fora do contexto das cooperativas é o de pequenas áreas, com utilização de mão de obra familiar, com destaque para os polos situados na Região da Serra de Petrópolis - RJ, Região da Serra Gaúcha - RS, Região de Barbacena - MG, Serra de Ibiapaba - CE e Região de Marialva - PR. Entretanto, o nível tecnológico na produção desses polos é baixo, tanto na estrutura física como no uso de material genético mais atualizado, não possuem câmaras frias para armazenamento, realizam o transporte até os seus clientes de maneira inadequada, sem a utilização da cadeia de frio. Essas deficiências geram maiores custos de produção e produtos com qualidade inferior, quando comparados aos comercializados nas Cooperativas que dispõem de tecnologias produtivas e alta produção por metro quadrado.

\subsection{O mercado de flores no Brasil}

Até os anos noventa, o consumo de flores no Brasil era incipiente, regionalizado e concentrado nas regiões produtoras. A partir de meados da década de 1990 até o ano 2000, houve uma expansão do consumo de flores, decorrente da elevação da renda média da população e do desenvolvimento de cidades, distantes do eixo Rio de Janeiro e São Paulo, como polos regionais, gerando uma demanda adicional importante ao segmento.

Com a ratificação de adesão do Brasil a Lei de Proteção de Cultivares (LPC) em 1999, empresas holandesas, detentoras de grande know-how em floricultura, aproveitam-se dos laços culturais com a cidade de Holambra para expansão no mercado nacional. Isso possibilitou aos produtores nacionais acessarem material genético de alta qualidade, podendo produzir "flores e plantas que estão mais próximas das necessidades dos consumidores, melhoria da qualidade do produto, diminuição de perdas pela maior 
resistência a doenças e pragas, com consequente redução de custos e maior durabilidade pós-colheita" (SÁ; SAES, 2015 p. 8).

Concomitante ao desenvolvimento regional ocorreu a evolução das condições de infraestrutura logística, tanto em relação às estradas, como dos caminhões refrigerados utilizados para o envio dos produtos a esses mercados. Além disso, outros fatores determinantes para o aumento do consumo e das vendas de produtos, para além da cesta básica, foram a maior eficiência das redes varejistas, a qualidade dos produtos comercializados e a ampla disponibilidade desses produtos em várias regiões do Brasil a partir de 2000 até 2014.

No período de 2010 até 2014, os gastos com festas e cerimoniais tiveram um crescimento de 100\%, sendo o casamento o evento principal em contratação de serviços de decoração (SEBRAE, 2015). Entretanto, a partir da crise de 2014, verificou-se uma tendência em consumir produtos com maior durabilidade e com baixa dificuldade de manutenção pós-compra (menor frequência de rega, pouca influência da incidência de luz), com destaque para a orquídea e suas mais diversas espécies e variedades comercializadas pelo canal de vendas do varejo alimentar, com ofertas de produtos ao longo de todo ano aos consumidores.

No geral, o mercado de flores e plantas ornamentais pode ser classificado em três grupos: a) flores e plantas verdes em vasos, b) flores e folhagens de corte, que no geral são hastes de flores ou folhagens colhidas/cortadas a partir de suas plantas e que representam 30\% do mercado nacional, e c) plantas para paisagismo e jardinagem, normalmente acondicionadas e comercializadas em sacos plásticos para o mercado profissional de jardinagem e paisagismo e que representam $31 \%$ do mercado brasileiro. $O$ modelo do cooperativismo tem sido predominante na organização do segmento de flores e plantas ornamentais.

Tabela 3 - Estimativa do faturamento na cadeia de flores e plantas ornamentais do Brasil

\begin{tabular}{lccc}
\hline Categorias & $\begin{array}{c}\text { Faturamento nos estados } \\
\text { pesquisados (R\$) }\end{array}$ & $\begin{array}{c}\text { Faturamento no Brasil (R\$) } \\
\text { folhagem de corte }\end{array}$ & $\begin{array}{c}\text { Participação no } \\
\text { Brasil (\%) }\end{array}$ \\
Flores e folhagens de corte & 515.896 .321 & 632.393 .664 & $30 \%$ \\
$\begin{array}{l}\text { Flores e plantas de vaso } \\
\text { Plantas ornamentais e para }\end{array}$ & 666.229 .139 & 803.845 .589 & $39 \%$ \\
paisagismo, exceto grama & 425.343 .026 & 652.776 .262 & $31 \%$ \\
\multicolumn{1}{c}{ Total } & 1.607 .468 .487 & 2.089 .015 .516 & $100 \%$ \\
\hline
\end{tabular}

Fonte: compilado de Neves et al. (2015) e Ibraflor (2015)

\section{CONTEXTO DE ATUAÇÃO DA COOPERATIVA ESTUDADA}

O foco deste estudo está no novo modelo de comercialização de uma cooperativa fundada por um grupo de produtores de flores da Região de Holambra - SP. Atualmente, além da sede, possui quatro unidades de negócios, com estrutura de recepção, armazenagem e distribuição de flores, localizadas em São Paulo (Capital), Brasília (Distrito Federal), Campos de Holambra (Município de Paranapanema - Estado de São Paulo) e em Ubajara (Ceará). Congrega 84 cooperados, concentrados nos Estados de Minas Gerais, Ceará, São Paulo, Distrito Federal, Paraná e Espírito Santo, totalizando 270 hectares de produção em estufa, o chamado cultivo protegido.

A Cooperativa Estudada é especializada na produção e comercialização de flores de corte, tais como rosas, alstroemerias, lisianthus, lírios e outras flores silvestres, além de folhagens e produtos processados (buquês) e flores envasadas, totalizando mais de 400 variedades em seu portfólio exercendo um papel fundamental na comercialização dos produtos gerados/produzidos pelos cooperados.

\subsection{Modelo de negócios da Cooperativa}

Desde o seu início o objetivo da Cooperativa Estudada é criar condições adequadas de vendas para todos os seus produtores, desde os menores até os mais organizacionalmente estruturados. Para tal, a inovação tem sido um dos eixos estratégicos do seu modelo de negócios. 
A Cooperativa Estudada estabeleceu as suas estratégias de comercialização sob quatro premissas: a) plantas são semiperenes e produzem hastes todos os dias ao longo de 4 a 7 anos; b) o mercado valoriza o frescor do produto, sendo um fator essencial para o bom posicionamento de preços; c) a durabilidade dos produtos, pós-colheita, é reduzida, principalmente quando comparada aos produtos do segmento de flores em vaso; d) o ciclo produtivo das plantas de flores de corte é influenciado por variações climáticas, de temperatura, de umidade e de luminosidade.

A partir dessas premissas, o modelo comercial da Cooperativa Estudada tem por diretriz realizar negociações rápidas e eficientes para os cooperados, ter preços justos e dirigidas para clientes com bom histórico de pagamentos, dentre eles clientes estratégicos como atacadistas que disponibilizam produtos para floriculturas e decoradores de diversas regiões no Brasil.

A produção no campo ocorre todos os dias e não pode parar. O seu ritmo diário é direcionado por três grupos de forças que modelam a oferta de produtos no segmento: 1) demanda decorrente de eventos comemorativos tradicionais e culturais; 2) renovação das áreas produtivas e investimentos em recursos tecnológicos para aumento da oferta diária de produtos mais resistentes a doenças/pragas e com maior longevidade pós-colheita; 3) amplitude térmica e o nível de umidade relativa do ar que interferem no ciclo de produção e na qualidade do produto.

Com esse cenário complexo de produção e gestão das vendas, a Cooperativa Estudada desenvolveu um modelo comercial que objetiva realizar vendas antes que os produtos sejam colhidos nos sítios, ou seja, ao serem recepcionados em sua unidade central esses produtos já estariam com o status de "flor vendida", reduzindo-se com isto o risco da perda de vendas e a especulação sobre excesso de estoques disponíveis.

Para tal, investiu-se no desenvolvimento de uma equipe instalada na Unidade Sede, para negociar diariamente com clientes em todo território nacional, por meio de um sistema de ofertas on-line, inédito no mercado de perecíveis à época, contudo, nos primeiros anos o modelo passou por dificuldades advindas principalmente da falta de recursos tecnológicos para acesso e conectividade necessários à viabilidade do módulo de vendas em todo território nacional.

Diante dessas dificuldades, a Cooperativa Estudada iniciou as pesquisas para definir seu posicionamento estratégico no mercado nacional que resultaram em mudanças estruturais a partir de 2013. Essa busca contínua por um modelo ideal de comercialização incluiu discussões internas entre os membros do Conselho de Administração, formadores de opinião, consultores, workshops com produtores e, inclusive, viagens técnicas à Holanda.

Em 2014, a equipe de Tecnologia da Informação (TI) da Cooperativa Estudada desenvolveu um novo sistema operacional para vendas de produtos (Sistema Integrado da Cooperativa - SINC), que permitiu estabelecer um modelo de e-commerce $\mathrm{B} 2 \mathrm{~B}$, envolvendo os produtores cooperados, com seus inputs de ofertas diárias de produtos, e os clientes cadastrados, que passaram a ter acesso, 24 horas por dia ao longo dos 7 dias da semana, aos produtos disponíveis para venda, tornando-se o maior banco de ofertas de flores de corte on-line no Brasil.

O fluxo de comercialização da Cooperativa Estudada via SINC, ilustrado na figura 3, inicia-se pela definição da espécie e variedade de flor a ser plantada (definição cogerida com a equipe Cooperativa), sendo então, iniciada a negociação dos produtores com os breeders (fornecedores de mudas). Após a definição da variedade/híbrido, o produtor realiza a aquisição da semente, muda ou estaca para o plantio efetivo. 
Figura 3 - Fluxo da comercialização no modelo virtual SINC

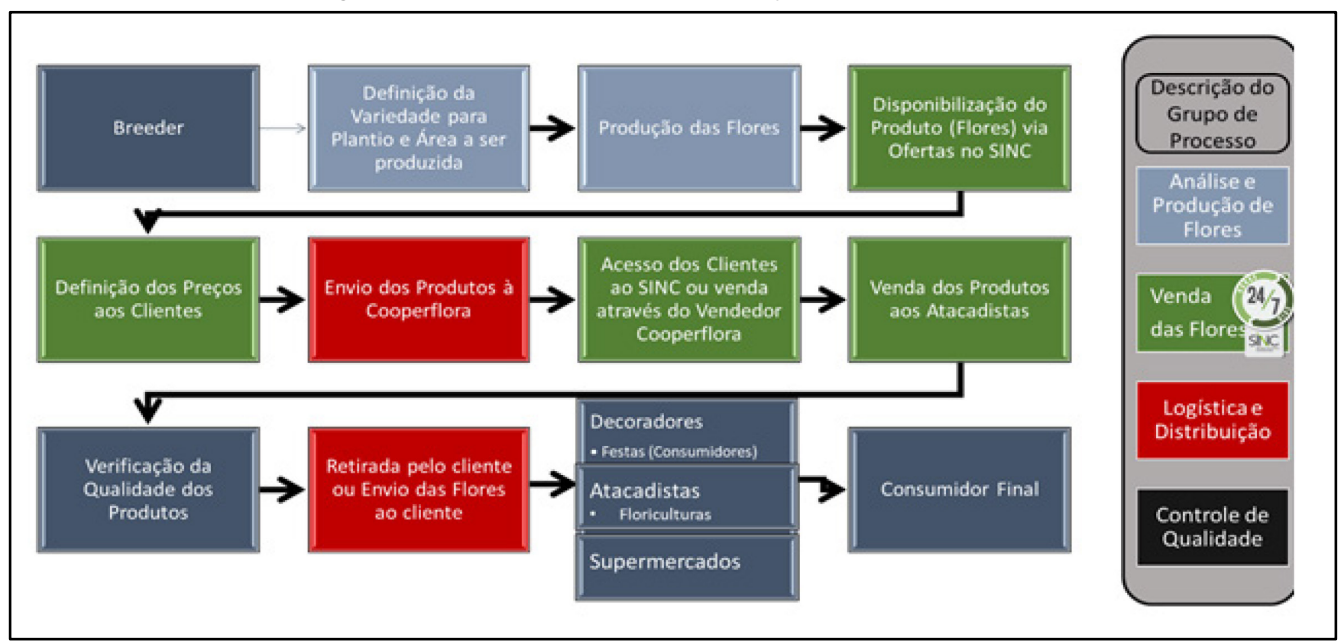

Fonte: Dados internos da Cooperativa Estudada (2018).

Na colheita o produtor embala e prepara o produto para o envio à Unidade da Cooperativa Estudada. Ao dar entrada os produtos podem ser expedidos imediatamente, em modelo crossdocking, ou vendidos em até dois dias (em média). Se o produto não for vendido durante esse período será descartado para a trituração, o qual passa a ser classificado como produto não faturado. Portanto, o fluxo de caixa é gerado pela cobrança de uma taxa percentual fixa sobre o preço efetivo de venda do produto ao cliente em cada transação e o valor gerado custeia a operação do dia a dia, os investimentos em infraestrutura e a manutenção do fundo de reserva para Provisão para Créditos de Liquidação Duvidosa (PCLD).

\subsection{Fatores críticos de sucesso}

No processo de avaliação da Cooperativa Estudada baseado nos brainstormings constantes entre cooperados, gestores, reuniões com clientes e produtores e, os membros do Conselho Administrativo, diagnosticou-se os principais fatores críticos de sucesso (FCSs) da atuação da Cooperativa para estabelecer índices de performance KPIs (Key Perfomance Index).

Além dessas ações, desenvolveu-se uma pesquisa de campo com 20 dos 30 maiores compradores anuais da Cooperativa, situados em diferentes regiões brasileiras, revelou os principais fatores críticos de sucesso no segmento de vendas para atacadistas de flores e plantas ornamentais, representados na figura 4.

Figura 4 - Valor percebido pelos atacadistas de flores e plantas ornamentais no Brasil

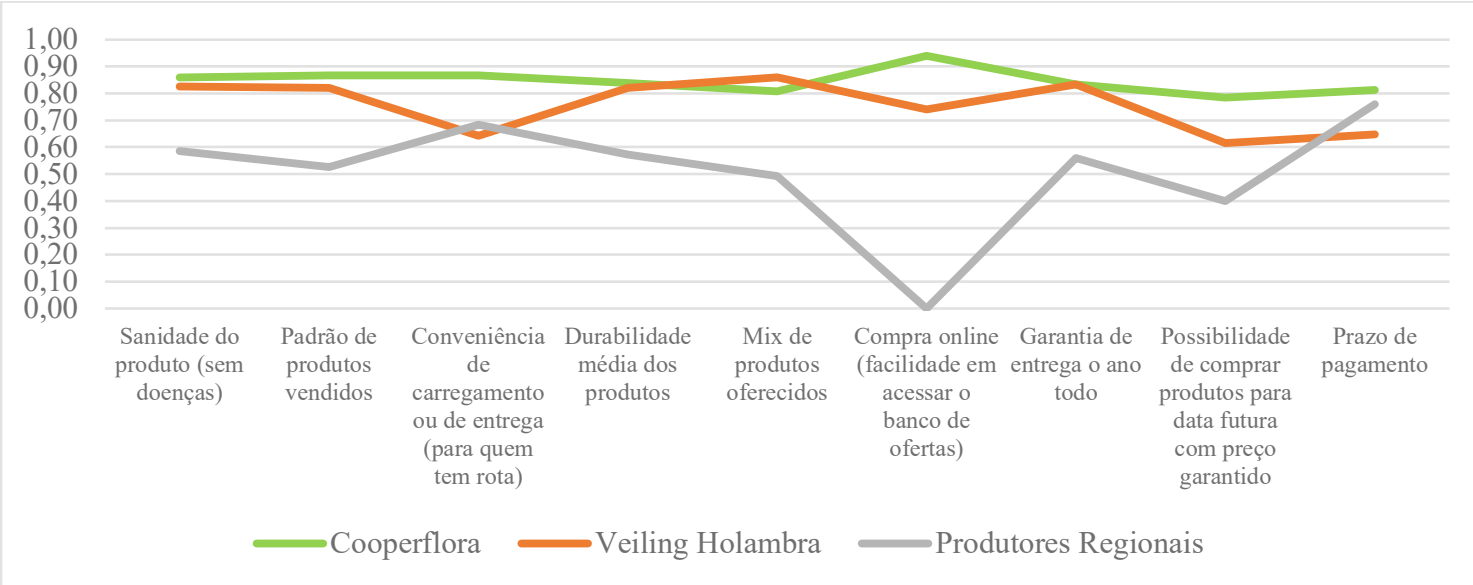

Fonte: Pesquisa de campo realizada com clientes da Cooperativa Estudada (2018) 
Na comparação entre as cooperativas verifica-se que há equilíbrio nas avaliações, não permitindo uma vantagem competitiva sustentável de longo prazo. Cabe ressaltar a existência de diferenças positivas de avaliação principalmente no que tange à conveniência de carregamento, compra on-line (facilidade de acessar o banco de ofertas), e possibilidade de comprar produtos para entrega futura com preço garantido e prazo de pagamento. Por outro lado, observou-se que o mix de produtos da Cooperativa Estudada é menor que o da Cooperativa Concorrente e que o seu sistema de vendas atual não proporciona muita competitividade entre os cooperados, e não há incentivo àqueles que disponibilizam para venda produtos com qualidade acima da média dos demais cooperados.

Já em relação aos produtores regionais, esses se destacam no fator conveniência de carregamento, o que os torna competitivos em termos da flexibilidade nas entregas aos atacadistas. Isso ocorre pelo fato de estarem próximos às regiões de atuação de seus clientes, podendo ter uma velocidade de resposta de reposição de produtos rápida e frescor de produtos. Outro fator de destaque desses produtores é o prazo de pagamento, pois aceitam cheques de terceiros (geralmente recebidos pelos atacadistas de seus clientes decoradores) e possuem flexibilidade de extensão de prazos, mesmo após o vencimento do prazo inicial negociado ter sido postergado pelos atacadistas.

Além da pesquisa de campo, a partir dos brainstormings internos realizados com os produtores cooperados, gestores e reuniões com os membros do Conselho de Administração, identificou-se outros pontos críticos que contribuem para um rápido reposicionamento estratégico de vendas diante das mudanças nos cenários de negócios, dentre eles: a) equipe comercial qualificada, conhecedora do mercado e apta para precificar os produtos independente do sistema de leilão Klok; b) constância na oferta e no volume de produtos com alta qualidade disponibilizados pelos cooperados ao longo do ano; c) reconhecimento de mercado como fornecedor especializado na comercialização de flores de corte; d) capilaridade do serviço de entregas que abrange diversas regiões brasileiras; e) garantia da qualidade do produto ao cliente; $f$ ) presença de unidades de negócios em grandes centros de consumo que permitem um melhor entendimento das demandas e maior velocidade no reconhecimento das mudanças do mercado; g) possuir um Sistema de Informações do Marketing (SIM) melhor estruturado que o da concorrência.

Verificou-se também que a estrutura física da Cooperativa Estudada restringia avanços para a comercialização de produtos envasados com maior valor de venda e geração de receitas com alocação de espaços para os clientes e que também gera recursos adicionais com serviços de material circulante (carrinhos de transporte de flores e plantas, bandejas plásticas para transporte de vasos e cestos plásticos para transporte de flores de corte).

Em continuidade à busca de um novo modelo de negócios para melhorar ainda mais o seu posicionamento estratégico no mercado, a Cooperativa Estudada iniciou um amplo diagnóstico para identificar novas oportunidades de mercado no sentido de impactar positivamente o consumo e potencializar o seu crescimento

\section{DIAGNÓSTICO DA OPORTUNIDADE}

O modelo de comercialização da maior cooperativa mundial de flores, a holandesa Royal FloraHolland, serve de referência para se estabelecer os preços no mercado europeu. Trata-se do sistema de leilão reverso Klok, em que a comercialização é encerrada quando os valores mínimos pré-estipulados pelos cooperados para cada produto é atingido, não havendo comprador ao atingi-lo, o produto é triturado e descartado no mesmo dia.

A partir de 2013, a Royal FloraHolland diagnosticou uma queda na participação de vendas pelo sistema de leilão Klok decorrente dos potenciais prejuízos aos cooperados nos casos de descarte. Quando o preço mínimo do produto não é atingido, o cooperado, além dos custos incorridos no processo de colheita, padronização, acondicionamento na embalagem e frete, também arca com a taxa de comercialização e descarte do produto. O sistema de leilão Klok também é adotado no Brasil pela maior concorrente da Cooperativa Estudada. 
Portanto, o leilão Klok apresenta custos de comercialização e de transação que independem da efetivação da venda ao cliente, com isso, o modelo de comercialização da Royal FloraHolland está migrando para um sistema de leilão virtual. Como a Royal FloraHolland serve de benchmarking para a Cooperativa Concorrente, há expectativa que esse novo sistema seja adotado também no Brasil. Entretanto, realizar o leilão sem a presença física dos produtos e compradores é um grande desafio devido às restrições técnicas relativas à velocidade de conexão e por fatores psicológicos, uma vez que um dos esteios para o sucesso do leilão é a percepção visual, tanto do volume de produtos quanto da quantidade de clientes interessados.

Outros fatores restritivos para o leilão virtual é a assimetria de informações e as inabilidades computacionais para definir o volume a ser enviado em cada dia de operação do leilão que limitam a perspectiva de vendas do produtor. Como exemplo recente, destaca-se o índice de assertividade para produtos não faturados do mês de janeiro de 2018, em um único dia, para o produto Rosas, que ficou acima de $30 \%$ (informação verbal) ${ }^{1}$. Com isso, o sistema virtual poderá gerar uma perda significativa em relação ao modelo presencial que ainda é uma referência mundial para a comercialização de flores e plantas ornamentais.

Por outro lado, a pesquisa conduzida pela empresa Forrester, realizado em 2015, evidenciou que aproximadamente $75 \%$ dos compradores do mercado de B2B afirmaram ser mais conveniente comprar por meio de um website do que realizar a compra por meio de um representante comercial. Na mesma pesquisa $93 \%$ dos respondentes disseram que, ao definirem seu produto de compra, preferem comprar on-lineao invés de acionarem o representante comercial.

Os estudos recentes de Almquist (2018) também revelaram que mais de $70 \%$ dos compradores da geração millenia/ realizam pesquisas genéricas em sites de pesquisa, como Google e Bing, sobre a demanda requerida para compras técnicas antes de contatarem efetivamente as empresas e seus vendedores.

Essa mudança de hábitos caracterizada pelo aumento dos mecanismos digitais no processo de compras B2B detectada nos departamentos de compras das organizações e também pela entrada de compradores da geração millenial no mercado B2B, veio ao encontro das discussões que estavam sendo desenvolvidas na Cooperativa Estudada em busca de um novo modelo negócios, que fosse capaz de reunir melhorias em seu sistema de comercialização para gerar maior valor ao cliente e ao cooperado.

Considerando-se os fatores críticos de sucesso da Cooperativa Estudada em relação aos seus concorrentes, ficou ressaltada a importância atribuída à compra on-line e à busca por novos horizontes e modelos de negócios. Então, diante das tendências macro ambientais e de mercado, assim como, do estágio do seu modelo de vendas on-line, a Cooperativa Estudada identificou uma oportunidade para criar valor aos negócios, minimizar as perdas e elevar a sua rentabilidade e a de seus cooperados: desenvolver e implantar um novo modelo de negócios baseado em plataforma digital para comercialização de flores e plantas ornamentais no Brasil.

O novo modelo de negócios viabiliza as vendas diretas e amplia o alcance de potenciais consumidores e novos cooperados com maior rapidez em diversas regiões do país, aproveitando-se das expertises da equipe de vendas e da equipe de TI adquiridas ao longo dos últimos anos com a operação do sistema SINC.

\section{MODELO DE NEGÓCIOS EM PLATAFORMA}

O conceito de negócios em plataforma sempre existiu. Supermercados e shoppings realizam a conexão entre os fabricantes e os consumidores por várias décadas; os jornais unem leitores e os anunciantes; os planos de saúde conectam os pacientes a uma rede de profissionais da medicina e vice-versa. (EISENMANN; PARKER; VAN ALSTYNE, 2009).

No sentido lato sensu, as plataformas de produtos e serviços são modelos de negócios que juntam grupos de usuários em dois ou mais lados de conexão, criando valor para todos envolvidos, em que a sustentabilidade financeira advém, basicamente, da cobrança de taxas de acesso à plataforma (GRAHAM, 2013; ZHU; FURR, 2016). Neste estudo, a plataforma digital é definida e entendida como um mecanismo de "produtos

\footnotetext{
${ }^{1}$ Diretor da Cooperativa Estudada. Entrevista realizada em outubro de 2018.
} 
e serviços que trazem para um mesmo ambiente grupos de usuários em dois lados de uma rede" (EISENMANN; PARKER; VAN ALSTYNE, 2009).

As primeiras plataformas digitais surgiram quando o eBay e a Craiglist lançaram suas plataformas abertas, em que os dados, as imagens, a descrição, os termos da venda e a precificação eram feitas diretamente pelos produtores sem interferência das empresas que conectavam produtores e consumidores (HAGIU; ALTMAN, 2017), reduzindo com isso os custos de transação e os gastos com infraestrutura física e ativos pelo uso intensivo da tecnologia da informação. (VAN ALSTYNE; PARKER, 2017).

Portanto, as plataformas digitais têm como premissa a orquestração dos recursos e dos integrantes da rede que as compõem. Segundo Libert, Beck e Wind (2016) esses modelos de negócios geram valor por meio da troca de relacionamentos e o capital das empresas orquestradoras é o networking, assim a facilitação das interações e o gerenciamento dos relacionamentos são as prioridades essenciais na gestão das plataformas com vistas à criação de externalidades de rede positivas.

O efeito da externalidade de rede é caracterizado quando a participação se torna cada vez mais atrativa para cada indivíduo quando outros indivíduos também começam a participar da rede (ROHLFS, 1974). Entretanto, segundo Parker, Van Alstyne e Choudary (2016), os efeitos de rede em uma plataforma podem ser positivos ou negativos. Positivo, quando a plataforma possibilita trocas significativas de valor para todos os usuários da comunidade que ela orquestra e, nesse caso, a vantagem competitiva dessa plataforma será ampliada. Já o efeito negativo é gerado principalmente quando há pareamentos indevidos ou dificuldades para que um pareamento assertivo entre produtores e consumidores ocorra em função de uma curadoria incorreta realizada pelo orquestrador de rede.

Portanto, um dos maiores desafios à criação da plataforma digital é a definição do número de usuários na rede, pois, uma base ampla desses participantes é essencial para que o efeito de rede seja efetivo, ou seja, é necessário ter uma massa crítica de fornecedores e, para atrair fornecedores, é preciso ter mais compradores até atingir uma massa crítica de participantes (ROCHET; TIROLE, 2003). Entretanto, no modelo de negócio B2B o número de consumidores não é tão importante quando comparado com o volume de negociações efetivadas, portanto, o número de participantes não será uma restrição no caso da Cooperativa Estudada uma vez que a sua base de usuários já está pré-alicerçada na atual base de vendas do sistema SINC.

\subsection{Modelo da plataforma digital da Cooperativa Estudada}

A oportunidade de criar uma plataforma digital para a comercialização dos produtos mostrou-se viável e compatível com seu sistema de vendas SINC utilizado pela Cooperativa Estudada nos últimos anos. Segundo Edelman (2015, p.7), “Construir um negócio compatível com sistemas legados, muitas vezes, pode ser a chave para um lançamento bem-sucedido". Desse modo, um dos pontos importantes a observar no desenvolvimento da plataforma é a evolução das interações que geram valor com vistas ao sucesso e à perenidade do negócio.

Para tal, a plataforma digital de negócios B2B da Cooperativa Estudada segue as recomendações de Legner (2008), passando-se de uma primeira geração de e-commerce que provê serviços básicos como efetivar a compra de produtos disponíveis por meio de uma interface baseada na web para um maior nível de serviços adicionais como a compra antecipada proporcionada pelo desenvolvimento de canais alternativos de comunicação para melhorar o desempenho das vendas, como é o caso iniciado pela Cooperativa Estudada com o sistema SINC.

A perenidade e o potencial de crescimento de uma plataforma, segundo Gawer e Cusumano (2008), também dependem de outros dois pré-requisitos: 1) deve possibilitar que ao menos uma função essencial seja ofertada ao mercado ou uma tecnologia que resolva um problema do segmento em que a plataforma pretende atuar e, 2) seja fácil de conectar para criar uma base de expansão para o uso.

Em geral, os modelos de plataforma de dois lados são de dois tipos: a TSP (two-sided platform) e a multifacetada ou multilateral MSP (multi-sided platform). A plataforma TSP, um caso específico da multifacetada MSP, caracteriza-se pela criação de valor conectando dois grupos distintos e interdependentes de clientes, enquanto o modelo de plataforma multilateral MSP reúne e coordena vários grupos de clientes, 
em número suficiente para gerar efeitos indiretos positivos na rede e tornar a participação valiosa para todos (HAGIU, 2006; EVANS; SCHMALENSEE, 2013; MUZELLEC; RONTEAU; LAMBKIN, 2015; PARKER; VAN ALSTYNE; CHOUDARY, 2016). Assim, as plataformas podem ser classificadas como corretores de negócios entre agentes desconhecidos que são aproximados pela tecnologia.

Na escolha do modelo de plataforma digital da Cooperativa Estudada levou-se em consideração a sua atuação no segmento business-to-business (B2B), cujas transações comerciais se dão entre empresas de distribuição (atacadistas), grandes decoradores e varejistas (redes de supermercado e hortifrútis) de um lado e os produtores do outro.

No modelo idealizado, o papel de curadoria das negociações dentro da plataforma digital é desempenhado pela própria cooperativa. Em relação aos produtores garantir-se-á que o produto negociado será entregue aos clientes por meio de três ações conjuntas, i) previsão da produção, que garante os volumes pré-negociados entre clientes e produtores, ii) acompanhamento da qualidade da produção, via indireta, sem a interferência técnica de consultoria agronômica e, iii) vistoria e controle de qualidade na recepção dos produtos nas Unidades da Cooperativa. Em relação aos compradores, a curadoria se dará objetivando a manutenção de uma base saudável de participantes, com histórico de pagadores e cumpridores de aspectos éticos negociais, evitando-se o oportunismo e negociações fora da plataforma sem a intermediação da Cooperativa.

A plataforma possibilita a conexão entre compradores e produtores de diversas regiões do Brasil para negociações de produtos disponibilizados online, sete dias por semana, ao longo de todo o ano, aumentando a visibilidade e o fluxo das negociações intermediadas da Cooperativa Estudada. Portanto, os efeitos de rede almejados ao longo da evolução da plataforma se distribuem em três fluxos de interações positivas ilustrados na figura 5.

O fluxo 1, destacado em preto, parte de uma base de produtores robusta, já consolidada na Cooperativa. Esse pilar proporciona que a plataforma contenha um número maior de lotes de ofertas, um número maior de produtos de diferentes produtores, uma possibilidade de maior número de variedades/híbridos e um número maior de produtos em cada uma das cores possíveis (as festas normalmente são demandadas por cores predominantes, o que facilita muito a oferta poder estar disponível para ser visualizada por cores). Esses reforços possibilitarão maior atração de clientes, maior disponibilidade de flores e plantas, trazendo também um incremento que outras regiões acessem a rede criada pela plataforma. Esses novos clientes em novas regiões atraem mais produtores para a plataforma.

Figura 05 - Modelo conceitual dos efeitos de rede da plataforma digital da Cooperativa

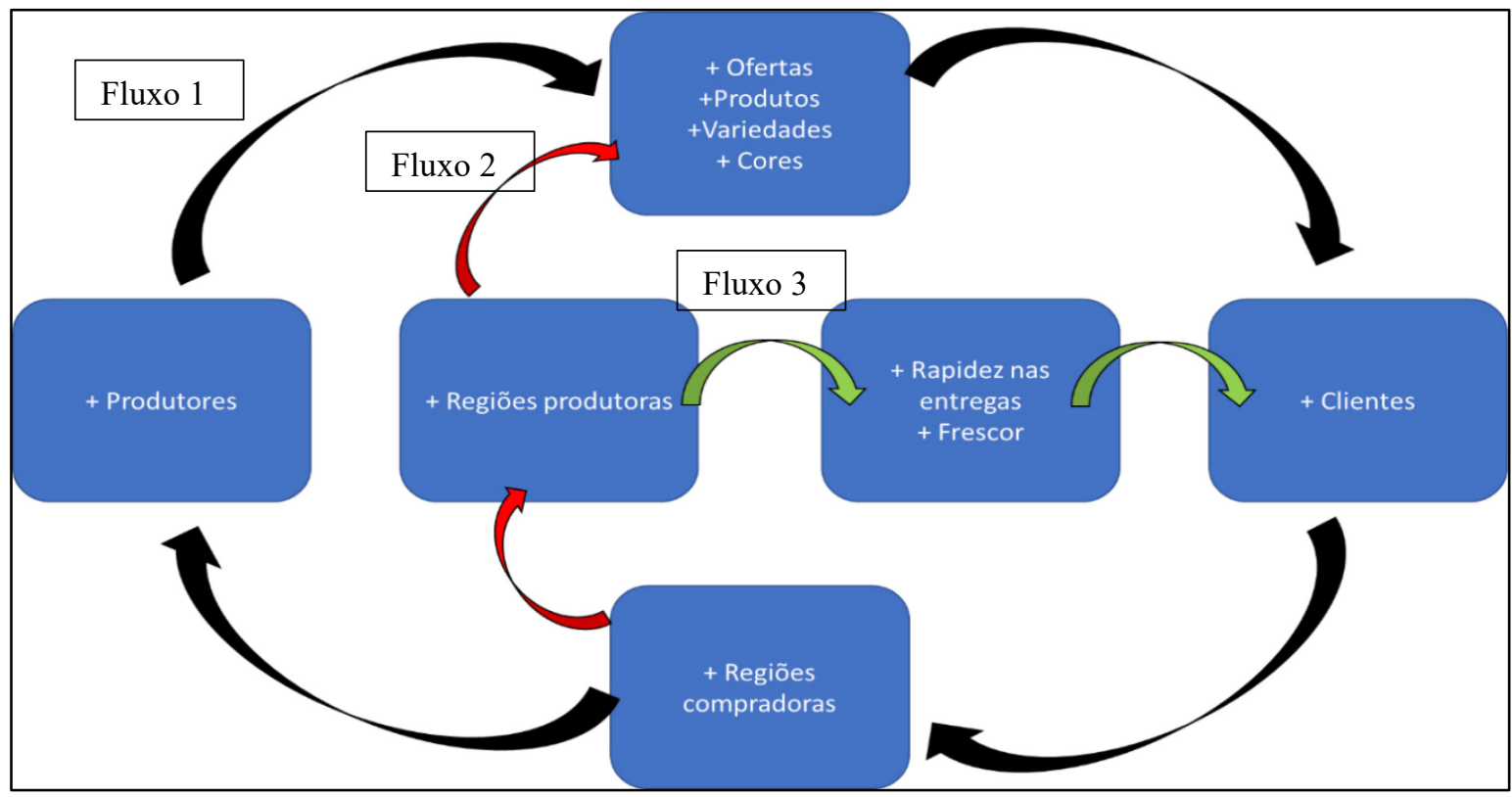

Fonte: Cooperativa Estudada, adaptado de Parker, Van Alstyne e Choudary (2016, p. 27). 
O fluxo 2, destacado em vermelho, propõe um efeito de rede pelo incremento de novas regiões produtoras, atraídas pelos novos compradores regionais da rede. Os novos produtores regionais integrantes da plataforma, geram novas ofertas, podendo criar e/ou reforçar o efeito de rede por meio de um maior número de lotes de ofertas, maior número de produtos de diferentes produtores, possibilidade de maior número de variedades/híbridos e um número maior de produtos em cada uma das cores possíveis.

O fluxo 3, destacado em verde, é gerado a partir da inserção dessas novas regiões produtoras na plataforma da Cooperativa, gerando maior rapidez nas entregas e mais frescor aos produtos para essas regiões, o que pode atrair novos clientes para a rede, reforçando com isso o efeito de rede global do fluxo 1 . Assim, ao adicionar um novo participante, a rede é aumentada para cada um dos demais participantes e com isso entrada de novos produtores e de novos clientes pode ser escalonável. Entretanto, para atingir o efeito de rede do fluxo 2 serão necessários investimentos na criação de uma nova Unidade de Negócios a fim de viabilizar a recepção e retirada de produtos.

O efeito de rede é essencial para a consolidação da plataforma e se dá quando os participantes percebem os seus benefícios. Contudo, a entrada de participantes deve ocorrer de forma equilibrada para não gerar efeitos unilaterais que, em geral, são negativos por afetarem o equilíbrio das negociações na rede (EISENMANN; PARKER; VAN ALSTYNE, 2009).

No caso da Cooperativa, o efeito de rede unilateral pode ser exemplificado quando há poucos produtores de uma determinada flor, gerando excessivo poder para esse lado da plataforma. De forma similar, a existência de poucos atacadistas numa determinada região pode criar dependência dos produtores a poucos atacadistas. Portanto, a escolha do nível ótimo de abertura a participantes é crucial para a criação e manutenção das plataformas.

Outro ponto de atenção é a forma de monetização utilizada para garantir a sustentabilidade financeira da plataforma. O modelo adotado na Cooperativa Estudada foi fundamentado nos trabalhos de Rochet e Tirole (2003), Gawer e Cusumano (2008), Eisenmann, Parker e Van Alstyne (2009), Parker e Van Alstyne (2018), os quais defendem que a sensibilidade à qualidade é um bom indicador para saber qual lado da plataforma será subsidiado. Dessa forma, optou-se por cobrar do produtor uma taxa sobre a venda efetivada, modelo este já utilizado pela Cooperativa com o sistema SINC. A monetização também se dará pela comercialização de alguns serviços aos atacadistas, como a gestão dos cestos e prolongadores, utilizados no transporte das flores.

A boa gestão da plataforma pela Cooperativa é crucial para a criação de valor aos clientes e produtores em e proporcionar: 1) maior comodidade e conveniência durante o processo de compra online pelo acesso ao banco de ofertas de flores de corte; 2 ) o funcionamento vinte e quatro horas durante todos os dias da semana e; 3) a retirada da compra no mesmo dia em que a negociação foi efetivada ou num intervalo que vai desde o dia seguinte à compra até as próximas cinquenta e duas semanas (horizonte futuro de doze meses).

Com a plataforma digital os pedidos online são feitos de forma direta aos sítios com preços prédefinidos pela equipe comercial da Cooperativa Estudada. Essa nova opção de transação permite reduzir as assimetrias de informação, reunir maior transparência no processo e reduzir a percepção de incerteza dos cooperados e clientes e, com isso, a redução dos custos de transação nas negociações (SILVA; BRITO, 2013). Além das vendas diretas e da transparência o novo modelo proporciona negociações a mercado futuro, ou seja, a saída do produto do sítio ocorre com o status produto "vendido", intensificando o fluxo de comercialização e os rendimentos dos produtores, com a redução do percentual de descarte e de itens não faturados, diferenciais antes inexistentes aos produtores.

A compra direta na plataforma digital também aumenta as possibilidades de negócios da Cooperativa com um número maior das redes de varejo, tanto alimentares como não-alimentares, interessadas na venda de flores de corte. Além disso, reduz os riscos de inadimplência e gera ganhos operacionais à Cooperativa, uma vez que o aumento do número de clientes não implica diretamente no incremento da equipe de vendas, conceito conhecido nas plataformas digitais como escalabilidade. Outro ponto de destaque da plataforma é a utilização de dados históricos provenientes das negociações dos produtos, que permite os direcionamentos 
de ofertas e comunicações adequadas ao perfil do cliente e a comunicação de ofertas em momentos de baixa demanda ou em horários fora do padrão, como as madrugadas.

\section{CONSIDERAÇÕES FINAIS}

No presente trabalho fez-se um relato dos passos seguidos para a adoção e implantação da plataforma digital para a comercialização de flores e plantas ornamentais em uma Cooperativa. Ao longo do movimento de digitalização do sistema de vendas da Cooperativa Estudada houve discussões estratégicas importantes para o desenvolvimento das bases para a criação e a implantação da plataforma digital.

A proposta inicial do modelo de plataforma digital foi apresentada para os membros do Conselho Administrativo da Cooperativa em dezembro de 2016 e os potenciais impactos na comercialização de perecíveis foram bem recebidos. Em abril 2017 foi lançado o novo modelo de gestão das vendas do SINC e, a partir disto, iniciou-se uma curva ascendente de participação das vendas digitais. O novo sistema permitiu uma maior aproximação do produtor com o cliente e, com isso, a Cooperativa Estudada iniciou o seu papel de gestão e condução dessa nova dinâmica de relacionamento. Neste mesmo mês, as vendas por meio do SINC digital ultrapassam pela primeira vez o índice $25 \%$ sobre o total vendido a clientes atacadistas sem a intervenção da equipe comercial.

A implantação do modelo de plataforma digital representa um avanço no segmento da comercialização de flores e plantas ornamentais e uma oportunidade para criação de valor aos negócios da Cooperativa Estudada, aos seus cooperados e clientes com maior transparência, acessibilidade, velocidade, menores custos de transação e menores perdas geradas na comercialização dos produtos, tanto para vendas com retiradas imediatas quanto para entregas futuras dos produtos.

A aplicabilidade do novo modelo de gestão de vendas proposto para a plataforma digital é vista pelos resultados atingidos até o presente momento que, além da vantagem competitiva, tem criado conexões a partir dos efeitos de rede em diversas regiões brasileiras, inovando o modelo de comercialização no mercado brasileiro de flores e plantas ornamentais. A efetivação de negociações antes das colheitas dos produtos por meio da plataforma tem permitido preços médios superiores, quando comparado com a Cooperativa Concorrente.

Nas últimas semanas do ano de 2019, as vendas digitais atingiram 45\% do total de produtos ofertados, havendo produtores com mais de $50 \%$ de suas vendas sendo feitas pela plataforma digital. Esses índices tiveram a contribuição do lançamento da Plataforma Digital Mobile (SINC Mobile), tanto na plataforma Android como na IOS, permitindo, aos clientes da Cooperativa estudada, acessar e realizar suas compras via celular, em um aplicativo desenvolvido pela equipe de Tecnologia da Informação da Cooperativa.

A plataforma digital permite a interação com sistemas de gestão ERP das empresas, tanto de produtores, como de atacadistas/decoradores. Com isto, o modelo gerará uma base de dados de acessos e compras que orientará as ofertas futuras, tanto na questão de precificação como quanto ao melhor horário de compras. Esses dados também poderão ser utilizados em modelos preditivos para detecção de tendências quanto a cores como para determinadas espécies/variedades de plantas.

A complexidade do estudo é evidenciada por três fatores. O primeiro está na digitalização de um modelo de mercado historicamente pautado por negociações presenciais ou via telefone entre clientes e vendedores. O segundo, está relacionado à conquista da confiança do cliente para realizar compras sem nenhum contato com a equipe da Cooperativa Estuda, tendo somente informações digitais sobre o produto adquirido e o conhecimento real somente no momento do carregamento, ou, nos casos onde o serviço de fretes é feito pela Cooperativa, quando recebe o produto em seu depósito a algumas centenas de quilômetros do produtor. O terceiro fator está relacionado ao controle da qualidade com o aumento dos fornecedores em função dos efeitos de rede nas diferentes regiões produtoras brasileiras.

A implantação do novo modelo traz contribuições e oportunidades à Cooperativa Estuda no sentido de estender os negócios em plataforma para outros segmentos agrícolas de produtos perecíveis ou mesmo, no futuro próximo, a migração da plataforma de dois lados TSP para o modelo de multilateral MSP com a entrada de novos usuários, como fornecedores de produtos acessórios e fornecedores de fretes para o 
transporte de flores e plantas, num movimento exitoso para agregar valor a todos os participantes da plataforma.

O trabalho também traz contribuições acadêmicas no sentido de reunir maior entendimento sobre o tema, que é bem recente, e por estender a aplicação do modelo de negócios em plataforma digitais para o segmento de perecíveis, em especial, no segmento de flores e produtos ornamentais.

\section{REFERÊNCIAS}

AKEN, J. E. van; BERENDS, H.; BIJ, H. van der. Problem-solving in organizations. 2. ed. New York: Cambridge University Press, 2012.

ALMQUIST, E. How digital natives are changing B2B purchasing. Harvard Business Review. Disponível em: https://hbr. org/2018/03/how-digital-natives-are-changing-b2b-purchasing, 2018. Acesso em 15/04/2020.

EDELMAN, Benjamin. Como lançar sua plataforma digital. Harvard Business Review Brasil, 2015. Disponível em: https://hbrbr.uol.com.br/como-lancar-sua-plataforma-digital/. Acesso em: 15/04/2020

EISENMANN, Thomas R.; PARKER, Geoffrey; VAN ALSTYNE, Marshall. Opening platforms: how, when and why?. Platforms, markets and innovation, v. 6, p. 131-162, 2009.

EVANS, David S.; SCHMALENSEE, Richard. The antitrust analysis of multi-sided platform businesses. National Bureau of Economic Research, 2013.

GAWER, Annabelle; CUSUMANO, Michael A. How Companies Become Platform Leaders, MIT Sloan Management Review. Cambridge Vol. 49, Iss. 2, p. 28-35, 2008.

GRAHAM, Paul. The Platform Stack: For Everyone Building A Platform and For Everyone Else. [2013]. Disponível em: http://platformed.info/platform-stack/. Acesso em: 15 abr. 2020.

HAGIU, Andrei. Multi-sided platforms: From microfoundations to design and expansion strategies. Harvard Business School. Working Paper Disponível em: http://hbswk. hbs. edu/faculty/ahagiu. html [feb 03 2009], 2006.

HAGIU, Andrei; ALTMAN, Elizabeth J. Finding the platform in your product. Revista Harvard Business Review, v. 95, n. 4, p. 94-100, 2017.

INSTITUTO BRASILEIRO DE FLORICULTURA - IBRAFLOR. Mercado Interno 12.2014. Holambra, SP: IBRAFLOR, 2015. Disponível em: http://www.ibraflor.com/publicacoes/vw.php?cod=234. Acesso em: 03 de nov. de 2017

LEGNER, Christine. The evolution of B2B e-services from first generation e-commerce solutions to multichannel architectures. Journal of Electronic Commerce in Organizations (JECO), v. 6, n. 2, p. 58-77, 2008.

LIBERT, Barry; BECK, Megan; WIND, Jerry (Yoram). Network Revolution: Creating Value Through Platforms. [2016]. Disponível em: https://knowledge.wharton.upenn.edu/article/the-network-revolution-creating-valuethrough-platforms-people-and-digital-technology/. Acesso em 15 abr.2020.

MARCONDES, R. C. et al. Metodologia para elaboração de trabalhos práticos e aplicados:

Administração e Contabilidade. São Paulo: Editora Mackenzie, 2017.

MUZELLEC, Laurent; RONTEAU, Sébastien; LAMBKIN, Mary. Two-sided Internet platforms: A business model lifecycle perspective. Industrial Marketing Management, v. 45, p. 139-150, 2015.

NEVES, Marcos Fava et al. Mapeamento e Quantificação da Cadeia de Flores e Plantas Ornamentais do Brasil. São Paulo: OCESP, 2015.

PARKER, Geoffrey G.; VAN ALSTYNE, Marshall W.. Innovation, Openness \& Platform Control. Management Science, v. 64, n. 7, p. 3015-3032, 2018. 
PARKER, Geoffrey G.; VAN ALSTYNE, Marshall W.; CHOUDARY, Sangeet Paul. Plataforma: A Revolução da Estratégia. São Paulo: Editora HSM do Brasil, 2016.

ROCHET, Jean-Charles; TIROLE, Jean. Platform Competition In Two-Sided Markets. Journal od the European Economic Association, v. 1, n. 4, p. 990-1029, 2003.

RODRIGUES, A.C.D. ; CALDEIRA, A. . Renovação do modelo de negócio para a revitalização de um empreendimento do setor de tecnologia da informação. In: SEMEAD - SEMINÁRIOS EM ADMINISTRAÇÃO DA FEA-USP, 22., 2019, São Paulo. Anais do XXII SemeAd - Seminários em Administração da FEA-USP. São Paulo, 2019. Disponível em: http://login.semead.com.br/22semead/anais/arquivos/190.pdf. Acesso em: 15 abr. 2020.

ROHLFS, J. Theory of Interdependent Demand for a Communications Service. Bell Journal of Economics and Management Science, v. 5, n. 1, p. 16-37, 1974.

SÁ, Camila Dias de; SAES, Maria Sylvia Macchione. Propriedade intelectual na cadeia de flores e plantas ornamentais: uma análise da legislação brasileira de proteção de cultivares. Revista Brasileira de Inovação, v. 14, n. 1, p. 49-76, 2015.

SERVIÇO BRASILEIRO DE APOIO ÀS MICRO E PEQUENAS EMPRESAS - SEBRAE. Flores e plantas ornamentais do Brasil: volume 1 - o mercado brasileiro de flores e plantas ornamentais. Brasília, DF: SEBRAE, 2015.

SILVA, Adilson Aderito da; BRITO, Eliane Pereira Zamith. Incerteza, racionalidade limitada e comportamento oportunista: um estudo na indústria brasileira. RAM, Rev. Adm. Mackenzie, São Paulo, v. 14, n. 1, p. 176201, Feb. 2013 . Disponível em: http://www.scielo.br/scielo.php?script=sci_arttext\&pid=S1678$69712013000100008 \&$ Ing=en\&nrm=iso. doi.org/10.1590/S1678-69712013000100008.

TSUBOI, Nobuhiro; TSURUSHIMA, Hisao. Introdução à história da indústria de flores e plantas ornamentais no Brasil. São Paulo: Comissão Editorial da História da Indústria de Flores no Brasil, 2009.

VAN ALSTYNE, Marshall; PARKER, Geoffrey. Platform Business: From Resources to Relationships Platform Business. GfK Marketing Intelligence Review, v. 9, n. 1, p. 24-29, 2017.

VAN RIJSWICK, Cindy. World Floriculture Map 2016: Equator Countries Gathering Speed. Rabobank Relatory. nov.2016. Disponível em: https://research.rabobank.com/far/en/sectors/regional-foodagri/world_floriculture_map_2016.html. Acesso em: 15 abr. 2020.

VANDENBOSCH, B.. Designing solutions for your business problems: a structured process for managers and consultants. San Francisco: Jossey-Bass.andenbosch, 2003.

ZHU, Feng; FURR, Nathan. Saltando de produtos para plataformas. Harvard Business Review, v. 94, n. 4, p. 51-57, 2016. 